\title{
Measurement and Clinical Significance of Novel Inflammatory Biomarkers in Patients with Psoriasis and Cardiovascular Risk Factors for the Primary Care Practitioner
}

\author{
Carmen Rodríguez-Cerdeira ${ }^{1,2,3,4}$, Erick Martínez -Herrera ${ }^{3,4}$, Miguel Carnero-Gregorio ${ }^{1,5}$, Adriana López-Barcenas ${ }^{3,4}$, Mónica \\ Cordeiro-Rodríguez ${ }^{1}$, Gabriella Fabbrocini ${ }^{3,7}$, Ardiana Sinani ${ }^{3,8}$, Brunilda Bardhi ${ }^{3,9}$, José Luís González-Cespón ${ }^{1}$ \\ ${ }^{1}$ Efficiency, Quality, and Costs in Health Services Research Group (EFISALUD), Health Research Institute. SERGAS-UVIGO \\ ${ }^{2}$ Dermatology Department, Hospital do Meixoeiro and University of Vigo, Vigo, Spain \\ ${ }^{3}$ European Women's Dermatologic and Venereologic Society (EWDVS), Tui, Spain \\ ${ }^{4}$ Psychodermatology task force of the Ibero-Latin American College of Dermatology (CILAD), Buenos Aires, Argentina \\ ${ }^{5}$ Department of Molecular Diagnosis (Array \& NGS Division). Institute of Cellular and Molecular Studies - ICM, Lugo \\ ${ }^{6}$ Dermatology Department Manuel Gea González hospital, Mexico City, Mexico \\ ${ }^{7}$ Dermatology Service, University of Napoli Federico II, Naples, Italy \\ ${ }^{8}$ Dermatology Service, Military Medical Unit, University Trauma Hospital, Tirana, Albania \\ ${ }^{9}$ Venus private clinic, Tirana, Albania
}

${ }^{\star}$ Corresponding Author: Carmen Rodríguez-Cerdeira. Efficiency, Quality, and Costs in Health Services Research Group (EFISALUD), Health Research Institute. SERGAS-UVIGO; E-mail: carmencerdeira33@gmail.com

Received: December 14, 2019; Accepted: January 28, 2020; Published: February 17, 2020

\section{Summary}

Large part of the current research in the field of psoriasis is directed towards identifying and characterising new biomarkers, for both diagnostic and prognostic purposes at clinical settings. This will help in developing prompt and effective therapeutic approaches, particularly to manage the cardiovascular risk factors often associated with psoriasis, to reduce cardiovascular morbidity.

This review highlights the biomarkers that have been identified to date, that are accessible and very useful to primary care physicians (PCPs), because, in most cases, these are the first indicators of psoriasis in the patients. We have focussed on the inflammatory and oxidative stress pathways to identify inflammatory biomarkers that link cardiovascular disease (CVD) risk with psoriasis, in both sexes. In addition, we have separately collated the information specific to women, unlike previous reviews.

Our review also emphasises the importance of staying abreast of the advances in the field, to understand the comorbidities of psoriasis. With new therapeutic approaches that offer novel treatment options, chances of detecting the comorbidities, even in their subclinical phase, improve. This can lead to accelerated clearance of skin lesions, and improved quality of life for the patients.

Key words: Psoriasis comorbidities, cardiovascular risk factors, inflammatory biomarkers, new biological treatments, early clinical diagnosis of psoriasis, primary health care

\section{Introduction}

Psoriasis vulgaris is a chronic, immune-mediated, inflammatory, polygenic skin disorder. Its prevalence is approximately $2 \%$ in the general population. It has a universal occurrence with a very similar proportion in men and women [1]. It can appear at any age, but two peaks in age of onset have been reported: the first between 20 and 30 years, and the second between 50 and 60 years [2].

Plaque-type psoriasis is the most frequent presentation representing $90 \%$ of cases and clinically manifests as well-demarcated erythematous plaques covered by silvery-white scales. They are located mainly on the extensor surfaces of the extremities, scalp, sacral area, and umbilicus. Psoriasis has a notable effect on quality of life; patients often experience depression, anxiety, and stigma as well as suicidal behaviour [3].

As Surcel et al. and Benson et al. [4,5] the knowledge of the pathogenesis of psoriasis has evolved over the years. Currently, the roles played by interleukin (IL) -23, IL-17, IL-22, T helper (Th) -17 cells, Th-22 cells, regulatory T cells, transforming growth factor (TGF) $-\beta 1$ and IL-10 in the pathogenesis of the disease have been highlighted $[4,5]$.

It has been reported by Fernández-Armenteros et al. [6] that psoriasis is an independent risk factor for the development of coronary 
artery disease and acute myocardial infarction. Thus, patients with moderate and/or severe psoriasis have a higher risk of developing ischemic heart disease or cerebrovascular disease than the general population.

Kimball et al. [7] conducted a study with 1,591 patients with moderate or severe psoriasis, and, based on the Framingham table, they estimated the 10-year risk of coronary heart disease and stroke in this population. They verified that for patients with a Psoriasis Area and Severity Index (PASI) score ( $>20)$, the risk was estimated at $12.2 \%$ and $8.7 \%$, respectively.

$\mathrm{Hu}$ et al. [8] analysed the risk of stroke in patients with psoriasis. They found that psoriasis, in mild and severe forms, is an independent factor directly related to the development of stroke. They found no relationship between psoriasis and suffering or depression.

In a thorough study, different comorbidities are listed that may accompany psoriasis, noting that several treatments target interleukin (IL) 17. However, it is still unclear whether they should be used in patients who are at a higher risk of developing CVD. There are some studies that describe its efficacy in psoriasis patients who are affected by myocardial infarction, hypertension, and chronic renal failure [9].

Anti-IL17A/F treatment has been tested in a randomized, double-blind, placebo-controlled Phase 1 clinical trial. Changes were observed in liver enzyme levels, and clinical readouts, such as vital signs, electrocardiograms, or body weight. In this trial, no deaths were reported [10].

"Author last name" briefly describes biomarkers for systemic inflammation, noting that some are prognostic biomarkers, and that some are diagnostic biomarkers. A complete review of biomarkers is described here in our manuscript.

Thus, psoriasis can be considered as the amplifier of the inflammatory march if the metabolic disorder appears before the diagnosis of psoriasis [11].

Patients with psoriasis have been found to have increased arterial stiffness. Increased risk of hypercholesterolemia, atherosclerosis, metabolic syndrome, and insulin resistance may also develop after chronic vascular inflammation; improvement of psoriasis can lead to a reduction in aortic vascular inflammation [12]. Additionally, patients with psoriasis are more likely to have subclinical atherosclerosis, greater carotid artery intimal thickening, and substantial endothelial dysfunction than the general population. The inflammatory nature of atherosclerosis and psoriasis has been highlighted recently; both are associated with $\mathrm{T}$ lymphocyte-mediated adaptive immune events and mechanisms involving innate immunity [13].

Alexandroff et al. [14] reported that obesity and psoriasis produce subclinical inflammation characterized by an increase in the levels of pro-inflammatory cytokines such as IL-6, TNF- $\alpha$, and C-reactive protein (CRP).

Schäkel et al. [15] focused on the innate and adaptive immune system and found interactions among neutrophils, macrophages, TH1 lymphocytes, monocytes, platelets, and IL-17a, which have been implicated in the pathophysiology of psoriasis and atherosclerosis.
Chronic inflammatory systemic diseases (CISDs) are part of a spectrum of chronic diseases in which inflammation plays an important role in pathogenesis. CISDs and cardiovascular diseases, including atherosclerosis, share common pathogenic features in which inflammatory cytokines play an important role. Common pathogenic features include immunological processes (diseases mediated by Th-1 cells), inflammatory cytokine profiles, and the presence of inflammatory markers both locally and systemically. Activation of these inflammatory cells, together with the release of inflammatory cytokines and proteases, contributes to the development of psoriatic lesions and plays a major role in the breakdown of atherosclerotic plaques [14].

Boehncke et al. [16] found that reduced levels of adiponectin are associated with insulin resistance and several adverse vascular events and are inversely correlated with serum CRP in obese patients with diabetes and those with coronary artery disease. Risk factors for cardiovascular disease (obesity, insulin resistance, and dyslipidaemia) are associated with decreased levels of adiponectin and high levels of leptin. Elevated levels of leptin in patients with psoriasis are associated with overweight and obesity, but not with the severity of psoriasis [17].

The assessment of cardiovascular risk through scales helps in therapeutic decision making and in cardiovascular prevention. The following necessary variables were collected for the calculation of coronary risk using both the Registre Gironí del cor (REGICOR) and Systematic Coronary Risk Evaluation (SCORE) scales: age, sex, total cholesterol, high density lipoprotein (HDL) cholesterol, systolic blood pressure, diastolic blood pressure, smoking history, and antecedent of diabetes mellitus (DM).The calculation of the risk of cardiovascular death by SCORE is based on the figures of total cholesterol and for countries of low risk, it was based on the following: age, sex, total cholesterol, systolic blood pressure, and smoking history [18] or the JUPITER study where HDL was an inverse predictor of incident events and biomarker of residual risk [19].

However, there is a discrepancy in the estimation of these scales for cardiovascular risk since they have limitations. Comparative studies were performed among the SCORE, REGICOR, and Framingham scales in our setting, and discrepancies were found in the detection of high risk and therapeutic indications (SCORE favours intervention in women with hypertension and Framingham in men with dyslipidaemia). The SCORE has the aggravating circumstance that it only estimates cardiovascular mortality and not morbidity [18-20].

Other scales used to determine cardiovascular risk were the American Framingham and POOLED cohort [21]. In patients with moderate-severe psoriasis, it is probably convenient to multiply the score obtained according to Framingham or SCORE by 1.5 [22].

In Spain, the only valid scale is REGICOR, but it only measures coronary risk. European countries support the SCORE scale but it only measures mortality and does not include people over 65 years of age. Currently, some authors consider the English scale promoted by the National Institute for Health and Care Excellence (NICE) as one of the most complete. The scale is called QRISK. It is available online at https: //qrisk.org/three [23] is the 3rd version [24]. 
In any case it is convenient follow the guidelines proposed by Dauden et al. [2]. Following the Spanish recommendations, screening for cardiovascular risk factors should be performed every 6 months in patients with systemic treatment and yearly in patients with topical treatment.

In the study conducted by Cea-Calvo et al. [26], the presence of undiagnosed cardiovascular risk factors (CVRF) in patients with psoriasis was investigated. For this, 368 patients were recruited, with an average age of 48 years, $96 \%$ with psoriatic plaque, $23 \%$ with psoriatic arthritis, and $4 \%$ with other forms of psoriasis.

Through the measurement of blood pressure and fasting blood test, new cases of cardiovascular risk factors (CRFV) were detected in more than $27 \%$ of patients. In addition, the 10 -year cardiovascular risk was similar to that of patients with known CVRF [26] macrophages.

The PCPs are important in the evaluation of cardiovascular risks in patients with psoriasis, because often they are the only physicians to treat and follow up with these patients. Their role can be more effective, if they possess sound knowledge of these pathologies and training to handle and treat them [27]. Research on this disease is primarily directed towards identification and characterization of new biomarkers. In this review, information about the main diagnostic and prognostic biomarkers, and their responses to different treatments, were collected from the patients of psoriasis with cardiovascular risk. These data can be useful in clinical practice.

\section{Correlation between Psoriasis and Cardiovascular Functional Indices}

Moore et al. [28] reported that the development of an atherosclerotic plaque is one of the most important risk factors. It is a multistep process and inflammation contributes to both the development of atheroma itself and the eventual rupture of the plaque; the first step is altered endothelial function with a change in the normal homeostatic responses; the next step is the recruitment of macrophages into the developing lesion and the accumulation of lipid-laden macrophages (foam cells) to form a fatty streak and the formation of a more advanced fibrous lesion, which is covered by a fibrous cap. Then, it gradually develops into an advanced and complex lesion, continuing in thinning of the fibrous cap to create a potentially unstable plaque that can eventually rupture, which leads to thrombosis and clinical evidence of vascular occlusion [28].

Family history of atherosclerosis, metabolic syndrome, diabetes, obesity, increased levels of inflammatory molecules (Figure 1) [29], discontinuity in the follow-up of patients [30] with newly diagnosed hypertension, diabetes, and hypercholesterolemia were associated with higher cardiovascular events, and associated mortality, escalating the financial cost of the health care.

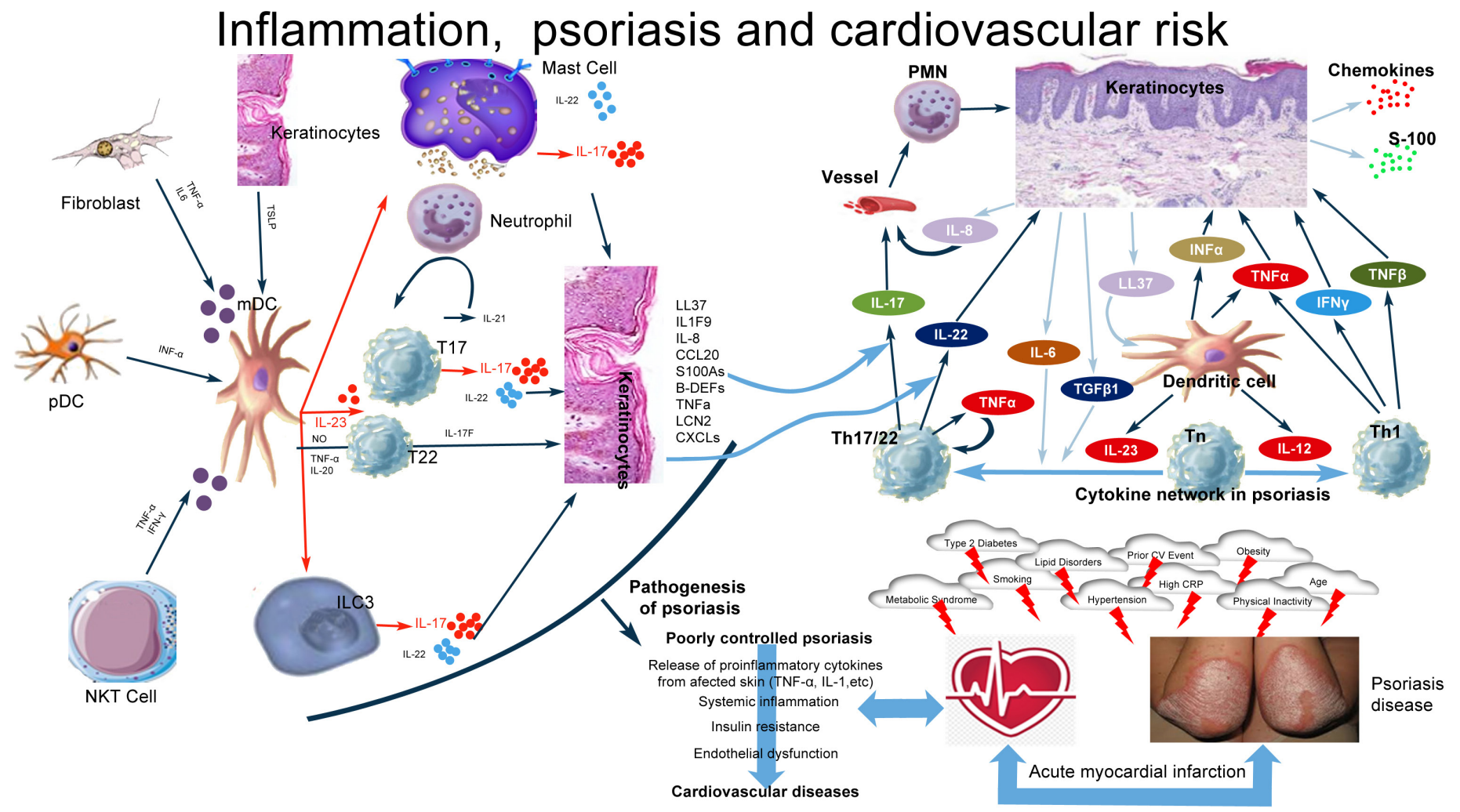

Figure 1. 
Histopathological changes observed in psoriasis are due to important and complicated interactions between keratinocytes, dendritic cells, T lymphocytes, neutrophils, and mast cells. IL-23, IL17, IL-22, Th-17 cells, Th-22 cells, regulatory T cells, TGF- $\beta 1$, and IL10 are involved in the pathogenesis of the disease. The IL-23/IL-17 axis is the main immune pathway in the pathogenesis of psoriasis. Multiple factors induce $\mathrm{mDC}$ activation with consequent IL-23 production (IFN- $\alpha$, TSLP), which, in turn, mainly stimulates T-cell subsets and also ILC3, mast cells, and neutrophils, which secrete IL-17. Other cytokines derived from T cells, mast cells, and ILC3 (IL-22, IL-17F, and IL-21) and from mDCs (TNFa, NO, and IL-20) are responsible for the development of psoriasis. T17 and T22 cells represent all T-cell subsets producing mainly IL-17 and IL-22.

Chronically released proinflammatory cytokines in patients with poorly controlled psoriasis pass into the circulatory system and potentiate and perpetuate systemic inflammation. This systemic inflammation causes obesity, hypertension, dyslipidemia, and type 2 DM. Additionally, this leads to an increase in insulin resistance, endothelial dysfunction, and the onset of cardiovascular diseases.

Environmental factors studied by Balak et al. [31] included infectious agents, a high-fat diet, smoking, alcohol consumption, low levels of antioxidants, and lack of exercise, as well as psychological stress, certain medications (antimalarial drugs, beta-blockers, lithium, and nonsteroidal anti-inflammatory drugs), and a history of skin disorders (e.g. psoriasis).

However, there is little data about subclinical alteration of myocardial function and adjacent vascular changes in patients with mild psoriasis. Milaniuk et al. [31] used two-dimensional stress echocardiography (2D-SE) for the quantification of alterations in all dimensions of the left ventricle. They reported that an increase in stiffness negatively affects cardiac function.

Dattilo et al. [33] evaluated cardiac performance and vascular rigidity in patients who had mild psoriasis and had no other risk factors or were undergoing treatment. The patients came from the department of Dermatology where they went periodically for follow up. Finally, 33 patients were included in the study sample. The control group consisted of healthy volunteers. The researchers found a significant correlation between global longitudinal strain and patient age. They also found that arterial stiffness values were significantly higher in psoriatic patients [33].

A study conducted by Sutton-Tyrrell et al. [34] showed arterial stiffness, a characteristic finding in patients with CISDs, is one of the most important determinants of increasing systolic blood pressure and pulse pressure; thus, it is a major cause of cardiovascular complications and events.

Ardic et al. [35] reported comparable left ventricle dimensions, wall thickness, and ejection fraction between patients with psoriasis and healthy controls.

Goga et al. [36] determined the presence of preclinical cardiac dysfunction in a cohort of 52 psoriatic patients without cardiovascular risk factors. They compared them with a control group. Both groups underwent echocardiographic conventional and tissue Doppler (TDI) studies. Left ventricular diastolic dysfunction was found in $36.5 \%$ patients in the psoriasis group versus $0 \%$ in control group. In addition, it was found that patients with psoriasis have a significant increase in mitral regurgitation [36].

Balbul-Sen et al. [37] conducted a cross-sectional and observational study with 65 patients with psoriasis and a control group. They verified that carotid intima-media thickness (CIMT) is a potential indicator of subclinical atherosclerosis in patients with psoriasis. Epicardial fat thickness (EFT) is proposed as a new cardiometabolic risk factor. They stated that EFT and CIMT are increased in patients with psoriasis, and that echocardiographic EFT will be correlated with CIMT in patients with psoriasis. This shows that echocardiographic study through EFT may be a marker of subclinical atherosclerosis and increased cardiovascular risk in patients with psoriasis.

Another comorbidity of psoriasis considered by Gisondi et al. [38] is the non-alcoholic fatty liver, which is currently considered to be the hepatic manifestation of metabolic syndrome. This condition is linked to an increased risk of future cardiovascular events independent of conventional risk factors [39].

Schiffrin et al. [40] found that a decreased flow velocity in the brachial artery indicated a risk of developing coronary artery disease.

El-Mongy et al. [41] reported that patients with psoriasis had more prevalent valvular regurgitation, abnormal diastolic relaxation, left ventricular hypertrophy, left ventricular diastolic dysfunction, left ventricular wall motion abnormalities. Mitral valve and tricuspid valve prolapse were found to be more prevalent in patients with psoriasis in a few studies, but in other studies, these results were not confirmed.

Echocardiographic findings from Biyik et al. [42] demonstrated that compared with the control group, patients with psoriasis had greater aortal diameter, greater septal and posterior wall thickness, more frequent tricuspid and mitral regurgitation, and increased systolic pressure in the right ventricle. Early atherosclerotic echocardiography predictors were found in the patients with psoriasis.

Goyal et al. [43] reported that psychological stress and depression have been increasingly in recent years and have been associated with multiple traditional cardiovascular risk factors. The amygdala regulates physiological and behavioural changes in response to stress and fear; using 18-fluorodeoxyglucose positron emission tomography computed tomographic (FDG PET/CT) imaging, the resting metabolic activity in the amygdala can be reproducibly assessed. Measures of stress-related neural activity are associated with anxious temperament and are upregulated in anxiety disorders, chronic stress, and depression. In 2017, Tawakol et al. [44] studied the importance of amygdalar activity (AmygA) with increased bone-marrow activity and arterial inflammation but they studied patients who did not have psoriasis. Goyal concluded that AmygA is strongly associated with aortic vascular inflammation (VI) and risk of major cardiovascular events. This association is partially mediated by upregulated hematopoietic system activity (HMPA). Psoriasis patients have elevated rates of anxiety and depression, and is also an independent factor directly related to development of CVD.

A retrospective study was conducted by Shiba et al. [45] to analyse the relationship between psoriasis and myocardial infarction, diabetes, 
and dyslipidaemia. They included more than 100,000 patients of all ages and performed multiple statistical analysis with the following results: patients with psoriasis have a higher prevalence of hypertension, DM, myocardial infarction, and hyperlipidaemia. There is an independent association between psoriasis and myocardial infarction.

\section{Correlation between Cardiovascular Risk and Psoriasis Severity Indices}

The importance of the severity of psoriasis in the development of cardiovascular disease is also supported by evidence of a correlation between PASI values and insulin secretion. Insulin resistance is a characteristic feature of metabolic syndrome. In patients with psoriasis, a statistically significant correlation has been observed between serum levels of resistin (a cytokine that is elevated in insulin resistance situations) and PASI [46]. These data indicate that the severity of psoriasis is related to an increased risk of cardiovascular complications and point to the pathogenic importance of a state of chronic inflammation in the development of vascular disease in these patients.

Prodanovich et al. [47] found a relationship between the severity of psoriasis with the risk for atrial fibrillation and ischemic cerebrovascular disease, with an atrial fibrillation incidence of 3.03 in patients without psoriasis compared to 5.96 in patients with severe psoriasis; similar figures were detected for ischemic cerebrovascular disease.

The risk score measured with the Framingham scale by Eder et al. [47] was significantly higher in patients with chronic plaque psoriasis than in the control group (grouped by age and sex). In patients older than 50 years, there was no correlation between the risk score and the severity of PASI [48].

To relate the severity of psoriasis to vascular inflammation, Naik et al. [49] recruited 60 patients with psoriasis and 20 controls, and measured the severity of the disease through PASI and vascular inflammation with the use of FDG PET/. They demonstrated that severe psoriasis is associated with atherosclerotic disease, and the presence of the disease alone increases cardiovascular risk, coupled with concomitant risk factors [49]. The contribution of PASI score in predicting vascular inflammation (aortic target-to-background ratio) beyond Framingham risk score and high-sensitivity C-reactive protein (hsCRP) was determined using likelihood ratio testing in nested models PASI score. The authors found that the severity of psoriatic skin disease increases vascular inflammation independently [49].

In a review by Prey et al. [50], they investigated the psoriasis cases (with different degrees of severity) and cardiovascular risk factors described in the literature between 1980 and 2009. Finally, 18 articles were selected from the main medical databases. There was an association between diabetes and psoriasis in 11 studies. The risk of diabetes was higher in patients with a moderate or severe degree of psoriasis [51,52]. Three studies showed an association between hypertriglyceridemia and psoriasis, and only one study showed an association between psoriasis and total cholesterol levels. None of the studies showed an association between psoriasis and risk of dyslipidaemia or HDL cholesterol levels.
The risk of hypertension was described in 10 studies compiled by Herron et al. [53] but a relationship between the level of risk and the degree of severity of psoriasis was not established. Eight articles showed the risk of obesity in psoriasis and reported that the risk increases directly depending on the severity of psoriasis. All articles showed an increased risk of metabolic syndrome (MS) in patients with psoriasis [53].

Chronic stress-related neural activity as measured by AmygA was higher in patients with severe PASI. Increased AmygA was related to the severity of psoriatic skin disease and subclinical cardiovascular disease (CVD). The amelioration of psoriasis with therapy was accompanied by reductions in AmygA, HMPA, aortic vascular inflammation, and stabilization of non-calcified coronary plaque burden (NCB). Stress affects the endocrine system, leading to upregulation of circulating catecholamines, glucocorticoids, and inflammatory cytokines, which subsequently leads to CVD. Psychological stress should be considered in evaluating CVD risk, especially in inflammatory disease states. The effect of reducing inflammation, as proven by improvement in PASI severity, on AmygA, HMPA, aortic VI, and NCB, [43].

In a study conducted by Uyar et al. [54], the mean serum concentrations of fetuin-A, alanine aminotransferase (ALT), and rheumatoid factor levels were found to be higher in patients with psoriasis. Median CIMT levels were significantly higher in patients with mild-to-moderate psoriasis compared to controls, but no correlations were found among the serum fetuin-A levels, CIMT levels, and PASI scores.

Rosa et al. [55] showed that $75 \%$ of patients with moderate or high risk presented a with a PASI below 10. Thus, although psoriasis patients had an increased cardiovascular risk, there was no relationship between severity of the cutaneous manifestations and a higher risk.

In a study by Gisondi et al. [56], using the Framingham risk score, they found the severity of cutaneous manifestations, measured by PASI, was associated with an increased cardiovascular risk.

Sorokin et al. [57] demonstrated that patients with psoriasis have a relative and absolute increase in circulating monocyte aggregates as well as an increase in intermediate monocytes, which correlates with an increase in the severity of PASI.

Sphingolipids, specifically ceramides (CER) and sphingosine1-phosphate (S1P), are signal molecules that are responsible for regulating cell growth, apoptosis, and immune reactions. Myśliwiec et al. [58] demonstrated that circulating levels of CER and S1P in plaquetype psoriasis were associated with disease activity through the PASI measure.

\section{Women, psoriasis and CV risk}

Interestingly, there were few instances of psoriatic women with increased risk of developing CVD. Some studies grouped patients based on sex, however, CVD risk was not always reported with patient sex. In this section, we collected information from the few studies that observed CVD risk in psoriatic women.

In Denmark, Blegvad et al. [59] studied 2,435 women with psoriasis $(2.90 \%)$ and 81,388 women without psoriasis and concluded 
that psoriasis is significantly associated with hypercholesterolemia and hypertension. Women with psoriasis have an increased risk of developing cardiometabolic disorders in early adult life. Screening for classic risk factors such as hypertension, hypercholesterolaemia, and hyperglycaemia, is advised. Additionally, preventing type 2 diabetes may be important when treating patients with psoriasis, particularly in younger patients.

In a study by Pietrzak et al. [60], 432 patients with psoriasis and a control group of 546 were selected. Both psoriatic and control patients showed that CVD occurrence increased with age and concluded that: a) the incidence of psoriasis and CVD in women increases with age, b) it is unclear whether menopause increases the risk of psoriasis, $c$ ) it is unclear whether menopause and resulting hormonal disturbances are independent CVD risk factors, and d) investigating whether hormone replacement therapy reduces CVD risk in psoriatic patients may be important.

Li et al. [61] conducted several studies on psoriatic women and the risk of developing CVD. In particular, the study published in Nurses' Health Studies (NHS) collected epidemiological information about the health status of women in different diseases, showing a strong relationship between psoriasis and CVD. In another study, there was a significantly higher risk of type 2 diabetes in psoriatic patients, and that this occurred particularly among younger women who had developed psoriasis at an early age [62]. Some of these patients eventually developed CVD. Li et al. [63] also showed that women with psoriasis had increased non-fatal CVD resistance, especially myocardial infarction. Therefore, women who developed psoriasis earlier, or those who have had it for a long time, presented an increased risk of myocardial infarction.

\section{Prognostic Biomarker}

The onset of psoriasis at an early age increases the risk of myocardial infarction. This appears to be due to an increase in the time of exposure to a chronic systemic inflammation. In a crosssectional study with 301 participants, Kumdai et al. [64] found that certain HLA antigens, including A30, B50, Cw6, and DR7.20, were associated with early-onset psoriasis.

On the other hand, Wongpiyabovorn et al. [65] reported that IL10 distal promoter polymorphisms are usually associated with lateonset disease.

Oxidized LDL (OxLDL) is very important in the exacerbation of atherosclerosis; thus, it is an important factor in the treatment of cardiovascular disease. In psoriasis, the efflux capacity of cholesterol is decreased, which changes after treatment. Activated oxidation lipid mediators (OMLs) abound in psoriatic skin, playing a critical role in the process of initial inflammation and resolution. A study by Sorokin et al. [57] with 252 patients with psoriasis and a control group measured LDL with modified oxidation, HDL, lipoprotein A, cholesterol efflux capacity, and size and number of lipoproteins. They observed an increase in oxidized Lp (a), Lp (a), and oxidized HDL. The activity of paraoxonase- 1 was increased by possible compensatory oxidative effect. It was concluded that psoriasis is associated with increased levels of some OMLs as opposed to healthy individuals.
OxLDLs have a direct association with the non-calcified plaque. The authors suggest that serum levels of OML could be useful as early markers in atherosclerosis by coronary computed angiography, which allows the quantification and characterisation of non-calcified plaque in the coronary arteries [57].

Dinić et al. [66] recruited 66 patients with chronic psoriasis plaque. The control group consisted of 20 patients with generalized eczema and 20 healthy controls, all of whom were between 18 and 60 years old, had no associated comorbidities, and underwent systemic treatment. Blood samples were taken and analysed. The values for the following were obtained: erythrocyte sedimentation rate (ESR), fibrinogen, PCR, Dimer-D, serum amyloid A, Apolipoprotein (Apo) A1, Apo B, Apo B / Apo A1 ratio, serum concentration of uric acid (SUAC), fasting insulin, Peptide-C, creatinine clearance obtained by Cockroft-Gault formula, microalbuminuria and proteinuria in $24 \mathrm{~h}$. Colour duplex Doppler ultrasound was also performed to measure the following: arteriovenous resistance; the thickness of the medial intima of the common carotid artery distal to the posterior wall of the carotid bifurcation; the femoral artery and its resistance and pulsatility indices; and maximum flow velocity of the femoral and brachial arteries. B-mode ultrasound was used. Patients with psoriasis presented with the parameters associated with cardiovascular risk, in addition to metabolic syndrome, even in the absence of other risk factors [66].

Three distinct monocyte populations have been identified and genotyped within human blood: classical monocytes (CD14 $++\mathrm{CD} 162)$, intermediate monocytes (CD14 ++ CD16 +), and nonclassical monocytes $(\mathrm{CD} 14+\mathrm{CD} 16++)$. Among the results obtained by Golden et al. [57], it was found that patients with psoriasis have a higher percentage of intermediate circulating CD14 + CD16 + monocytes compared to controls. This was obtained through peripheral blood samples, and/or biopsies in healthy controls and in patients with psoriasis. Systemic or topical therapy were not used for the preparation of mononuclear cell preparations in peripheral blood. It was also shown that the classical monocytes subset (CD14 $++\mathrm{CD} 162)$ correlates negatively with PASI, and the nonclassical monocytes $(\mathrm{CD} 14+\mathrm{CD} 16++)$ do not show any correlation [67].

The vascular uptake of fluorodeoxyglucose (FDG) is associated with unstable atherosclerotic plaques. A relationship was found between arterial inflammation detected by FDG PET/CT and the presence of high-risk coronary plaque, which is mainly composed of cells of the psoriatic plaques. This suggests a potentially shared immune mechanism and demonstrates the role of neutrophils in the perpetuation of psoriasis and their comorbidities; the downregulation of CD16 and CD62L in this sample indicates a decreased ability to mediate inflammatory damage and a greater activation state. It was also reported that S100A8/A9 proteins may serve as mediators or by-products in one of the potential pathays linking psoriasis severity and arterial inflammation, confirming the role of neutrophils in cardiovascular disease associated with psoriasis [49].

Ryan at al. [68] found microparticles present in the atherosclerotic plaque breakdown, which causes cardiovascular events. They also 
showed an increased concentration in these microparticles in patients with psoriasis.

Homocysteine is an amino acid produced in the liver that is involved in the pathogenesis of several diseases, including psoriasis. It increases the levels of oxidative stress and inflammation, and induces apoptosis of endothelial cells, which favours atherosclerosis; atherosclerosis is the most common cause of cardiovascular pathology such as myocardial infarction or heart failure. Homocysteine levels can be used as predictors for cardiovascular risk, and they are directly related to the severity of psoriasis [69]. Homocysteine plays an important role in the DNA methylation cycle, which is a process related to epigenetic mechanisms. Wang et al. [70] reported that several studies have observed that hyperhomocysteinemia reduces levels of DNA methylation, which is related to the pathogenesis of psoriasis. Genes that encode proteins such as HLA-DRB1, protein tyrosine phosphatase 1 (SHP-1), or different high proliferative potential colony-forming cells (HPP-CFCs) are hypomethylated.

Qi at al. [71] reported that methylene tetrahydrofolate reductase (MTHFR) participates in the irreversible conversion of a cofactor that participates in the remethylation of homocysteine to methionine. Only one polymorphism of the MTHFR gene $(677 \mathrm{C}>\mathrm{T})$ is related to psoriasis, and there are reports of the relationship between this polymorphism and cardiovascular diseases. This polymorphism is not a risk factor in the pathogenesis of psoriasis, but it can influence the severity of psoriasis.

Psoriasis in combination with obesity/MS produces greater systemic inflammation and greater oxidative stress, which promotes endothelial dysfunction and the formation of atherosclerotic plaques, which increase the risk of cardiovascular disease. Kaur et al. [72] found that obesity and psoriasis produce subclinical inflammation characterized by an increase in the levels of pro-inflammatory cytokines such as IL- 6 , TNF- $\alpha$, and CRP. The levels of CRP and IL-6 are related to the severity of psoriasis.

Psoriatic skin disease severity showed a linear relationship with AmygA, and was associated positively with subclinical cardiovascular disease, a higher Framingham risk score, more insulin resistance, and higher CRP levels. When psoriatic skin disease severity improved, there was a significantly concurrent decrease in AmygA, bone marrow activity, and aortic elasticity, and found beneficial effects of skin disease clearance on the amygdala and aorta after one year of treatment $[73,74]$.

The CRP is an acute phase reactant protein produced from hepatocytes within hours after being stimulated from infection, inflammation, or tissue damage. Its levels decrease rapidly after the stimulating factor has been eliminated or has responded to treatment. Uaratanawong et al. [75] showed that the hs-CRP level was significantly higher in the psoriasis group with a significant correlation between hs-CRP and PASI score after controlling for other confounding factors. A hs-CRP level greater than $0.69 \mathrm{mg} / \mathrm{L}$ could be the marker of worsening psoriasis. The keratinocytes in psoriasis lesions secrete tumour necrosis factor- $\alpha$ and interleukin-1, which can stimulate hepatocytes to produce hs-CRP. Furthermore, hs-CRP level can predict cardiovascular risk, including cerebrovascular and peripheral arterial disease (hs-CRP less than $1 \mathrm{mg} / \mathrm{L}$ as a low risk, 1-3 $\mathrm{mg} / \mathrm{L}$ as intermediate risk, and more than $3 \mathrm{mg} / \mathrm{L}$ as high risk for cardiovascular event). Although hs-CRP is not a specific marker and additional work will be imperative to validate this marker, it shows the inflammatory burden of psoriasis and could be a potential marker that can be used for grading psoriasis severity with great cost-effectiveness.

When assessing coronary artery disease and generalized atherosclerosis, CIMT is a good indicator of an increased risk of subclinical atherosclerosis. Fetuin-A is a serum glycoprotein that is synthesized mainly by hepatocytes, increases insulin resistance and dyslipidaemia and reduces ectopic calcification in vascular disease. There are reports on fetuin-A interacting with transforming growth factor (TGF)- $\beta$ and epidermal growth factor (EGF), which play an important role in the pathogenesis of psoriasis [76].

Ix et al. [77] reported that lower fetuin-A levels initiate calcium deposition within the vasculature but not atherosclerosis directly, and that they are independently associated with greater coronary artery calcification severity but not peripheral arterial disease. They observed a correlation between serum fetuin-A levels and fasting glucose, as well as between fetuin-A and LDL cholesterol, so it is recommended that physicians should measure CIMT rather than the less appropriate serum fetuin-A values when assessing the cardiovascular disease risk of patients with psoriasis.

Serum adipokines have been considered in the pathogenesis of the psoriasis and have been demonstrated to be associated with insulin resistance. Adiponectin, resistin, and leptin have possible antiatherogenic and anti-inflammatory properties by regulating energy homeostasis and increasing insulin secretion and sensitivity. Hyperleptinemia has contributed to cardiovascular risk in patients with the metabolic syndrome; adiponectin and leptin are predictors of microvascular complications in patients with type 1DM [17].

A study by Yazıcı et al. [78] included 65 patients with type $1 \mathrm{DM}$. Leptin levels were reported to be decreased in adult patients with type $1 \mathrm{DM}$ without association with CIMT. Resistin levels were decreased in adult patients with type $1 \mathrm{DM}$ and increased in patients with type 2 DM with CAD and was correlated positively with CIMT; increased resistin levels in patients with type $1 \mathrm{DM}$ seem to be suggestive of subclinical atherosclerosis. Leptin was associated with CIMT in patients with type $2 \mathrm{DM}$. Thus, after adjusting for other known predictors, only resistin was associated with subclinical atherosclerosis in this group of patients. Ataseven et al. [79] suggest that vaspin and VAP-1 may play a role in the pathogenesis of psoriasis and can be used as markers of the disease. Therefore, vaspin levels can be used as a marker of the severity of the disease.

\section{Diagnostic Biomarkers}

A strong expression of chemerin was observed by Nakajima et al. [79] in pre-psoriatic skin adjacent to active lesions and early lesions in the dermis. They also observed the presence of $\mathrm{CD} 15^{+}$neutrophils and $\mathrm{CD} 123^{+} / \mathrm{BDCA}-2^{+} / \mathrm{ChemR}_{2} 3^{+}$pDC. In skin from chronic plaques, chemerin expression was lower. Additionally, the segregation of neutrophils in epidermal microabscesses and a few plasmatoid dendritic cells (pDCs) in the dermis were observed [80]. 
Chemerin stimulates the chemotaxis of pDCs and neutrophils, and high systemic chemerin level was found as an independent marker of the metabolic syndrome. Recently, Albane si et al. [81] reported a strong expression of chemerin together with increased numbers of pDCs and neutrophils in the dermis of early psoriasis lesions.

Furue et al. [82] reported that condition which have been proposed include shared genetic factors, common inflammatory pathways, secretion of adipokines, insulin resistance, altered lipoprotein composition and function, angiogenesis, oxidative stress, microparticles, and hypercoagulability; CRP, Th1, and Th17 lymphocytes, resistin and leptin has been found to be elevated, with decreased serum levels of adiponectin. Psoriasis may induce systemic inflammation leading to insulin resistance, endothelial dysfunction, and the development of atherosclerosis and cardiovascular comorbidities in the psoriatic march.

Identification of serum biomarkers (CRP, soluble CD40 ligand, human matrix Gla protein and fetuin-A, serum YKL-40, GlycA, and complement C3) of systemic inflammation is important for assessing cardiovascular risk; adequate treatment for psoriasis may decrease the risk of cardiovascular comorbidities as a result of suppression of systemic inflammation [12].

A group of 74 patients with psoriasis and 65 healthy controls were studied by Vachatova et al. [83]. Individuals with insulin resistance, diabetes, and cardiovascular disease were included in the psoriasis group. None of them had treatments that could influence inflammatory reaction. Patients with psoriatic arthritis were excluded. The patients with psoriasis presented with higher diastolic blood pressure, MS, BMI, and hip circumference compared to the controls. Patients with psoriasis had higher levels of leptin, resistin, and lipoprotein-associated phospholipase A2 (Lp-PLA2) than controls. Among individuals with MS, those in the psoriatic patients group had higher CRP levels of leptin, resistin, and Lp-PLA2 than those of CG. Patients with psoriasis and MS had higher levels of leptin and Lp-PLA2 and lower levels of adiponectin than patients with psoriasis without MS.

The combination of psoriasis and MS increases the expression of inflammatory and anti-inflammatory cytokines and increases the risk of cardiovascular disease. Likewise, adipokines (leptin, adiponectin, and resistin) are involved in the pathogenesis of psoriasis and MS, and the levels of Lp-PLA2 indicate the presence of subclinical atherosclerosis and cardiovascular risk in patients with psoriasis.

Kiluk et al. [84] found that Lp-PLA2 is associated with an increased incidence of cardiovascular events but only a few studies have associated it with psoriasis.

Metabolomics may potentially explain the mechanisms of various diseases, facilitate early diagnosis, and identify possible therapeutic areas.

Wang et al. [85] presented a utility (mmPredict) to determine metabolomic biomarkers, which is complemented by current studies of metabolomic profiles that are based on patient data. This utility reveals the metabolites of psoriasis based on both genetic and phenotypic relevance (genome-phenome). It was shown in the study that mmPredict is more effective in identifying clinically relevant biomarkers in psoriasis than the genome-based approach. They are improving mmPredict to incorporate other types of data such as the phenotype of drugs and high-level diseases observed in humans.

Another study, conducted by Coimbra et al. [86], showed that inflammatory cytokines were involved in the pathogenesis of psoriasis such as IL-22, IL-17, IL-23, IL- 8, TNF- $\alpha$, and endothelial growth factor.

Ellulu et al. and Rodríquez-Cerdeira et al. $[87,88]$ reported that reduced levels of adiponectin are associated with insulin resistance and several adverse vascular events and are inversely correlated with serum CRP in obese patients with diabetes and those with coronary artery disease. Risk factors for cardiovascular disease (obesity, insulin resistance, and dyslipidaemia) are associated with decreased levels of adiponectin and high levels of leptin. Elevated levels of leptin in patients with psoriasis are associated with overweight and obesity, but not with the severity of psoriasis.

Excess fatty tissue, due to obesity associated with psoriasis, contributes to atherogenic dyslipidaemia, and several studies have associated atherogenic dyslipidaemia with increased blood levels of total cholesterol, triglycerides, LDL, and apolipoprotein A, and low levels of HDL and apolipoprotein B in patients with psoriasis.

In a study by Asha et al. [89], ox LDL is considered a marker of hyperlipidaemia and atherosclerosis. A few studies have shown increased levels of oxLDL in patients with psoriasis, which was consistent with the BMI. oxLDL/LDL ratio a better predictor for atherosclerotic risk as compared to LDL

Advanced oxidation protein products (AOPPs) and adipokines are also involved in the pathogenesis of endothelial dysfunction and atherosclerosis.

In other study conducted by Haberka et al. [90], patients with non-severe psoriasis had significantly increased impaired endothelial function and CIMT, and significantly increased serum levels of AOPPs and visfatin. Increased oxidative stress and serum visfatin levels are associated with a chronic inflammatory state; increased AOPP levels are associated with endothelial dysfunction (FMD), vascular remodelling CIMT, and increased serum visfatin levels, suggesting that increased oxidative stress is the main pathomechanism involved in cardiometabolic complications found in non-severe psoriasis.

In patients with psoriasis with a risk allele of FTO gene rs9939609, Tupikowska-Marzec et al. [91] suggested that they have an increased risk for more severe psoriasis and obesity, and may develop obesity-induced insulin resistance and therefore, CV risk.

As Barrera et al. [92] Vit D ot only to reduce its clinical severity, but also for delineating the risk profile for co-morbidities cardiac risk factors that may result from psoriasis [93].

Recently, a study in women conducted by Hruska et al. [94] showed a strong relationship between single nucleotide polymorphism (SNP) rs4597342 within the3'untranslated region (3'UTR) of integrin alpha M (ITGAM) with psoriasis susceptibility and severity. The 
associated risk was observed specifically for allele T of rs4597342, which introduces a binding site for miR-21 that is upregulated during psoriasis [94]. These markers are also linked to IgA nephropathy [95] and type 1 diabetes [96], which could be interesting diagnostic markers for CVD

\section{Treatment Biomarkers}

Reviewing the literature, we observed that patients with psoriasis receive suboptimal and disconnected attention and it leads to a decrease in the quality of life. As proposed by Gulliver et al. [97], the concept of treat-to-target, which has already been adopted for other conditions such as diabetes and dyslipidaemia, would be very beneficial for patients with psoriasis.

Treatment regimens should be individualized according to the risk factors of the patient, especially those with cardiovascular risk. The use of effective treatments is very important to help improve patient outcomes.

According to Caiazzo et al. [98], the introduction of biological therapy has greatly improved our therapeutic expectations and longterm control of the disease, and there is epidemiological evidence that it can also improve cardiovascular risk, as in patients with rheumatoid arthritis. However, some adverse effects of treatment with agents that block TNF- $\alpha$ have been described in patients with advanced congestive heart failure. Thus, special caution is required when these drugs are used in these patients.

Interleukins have recently been introduced or are under study for the treatment of psoriasis. Krueger et al. [98] reported that ustekinumab and briakinumab (ABT-874) are human monoclonal antibodies that target the p40 subunit common to both IL-12 and IL-23. Ustekinumab and other IL-12/23 inhibitors can increase the risk of cardiovascular adverse events, including st roke, MI, and cardiovascular death [99]. The main inflammatory cytokines involved in $\mathrm{CV}$ are summarized in Table $1[88,100-109)$.

In a study by Papp et al. [110] and Spuls et al. [111] with antiinterleukin-17-receptor antibody treatment, they concluded that patients with plaque psoriasis significantly improved. These were especially effective in hard-to-treat areas such as the scalp and nails; significant differences were observed with placebo with ixekizumab treatment. There was no evidence of cardiovascular risk in the treated patients. A more recent study by Lockshin et al. [112] was also not conclusive in terms of $\mathrm{CV}$ risk assessment.

The participation of nails also as Ventura et al. [113], it correlates positively with the early onset of psoriasis in the populations of Europe and America, which would be a marker of initiation of treatment as soon as possible.

Shih et al. [114] reported that the treatment of psoriasis with anti-inflammatory biological therapy reduces levels of oxHDL together with a decrease in non-calcified plaque in one year, so they suggested that serum levels of OML could be useful as early markers in atherosclerosis. These were measured with coronary computed angiography, which allows the quantification and characterization of the non-calcified plaque in the coronary arteries. It will be very important to investigate the factors for the oxLDL induction of LOX1 in psoriasis. LOX-1 receptor expression could be another novel treatment option for psoriasis and represents a very interesting and promising strategy.

Table 1. Involvement of inflammatory cytokines in cardiovascular risk

\begin{tabular}{|l|l|}
\hline Obesity & $\begin{array}{l}\text { IL-17A expression is upregulated in obesity [88]. } \\
\text { Cytokines such as TNF- } \alpha \text { and IL-6 are responsible for the } \\
\text { pro-inflammatory state of obesity [100]. } \\
\text { Adipose tissue of individuals with obesity leads to the } \\
\text { development of Th17 cells [88]. }\end{array}$ \\
\hline Diabetes & $\begin{array}{l}\text { IL-8, IL-17, IL-18 and IL-6 levels are increased in diabetes, } \\
\text { leading to insulin resistance. Increased levels of IL-6 and } \\
\text { IL-1 } \beta \text { also lead to insulin resistance [101]. } \\
\text { TNF- } \alpha \text { induces insulin resistance by reducing the tyrosine } \\
\text { kinase activity of the insulin receptor [102, 103]. }\end{array}$ \\
\hline Atherosclerosis & $\begin{array}{l}\text { Cytokine products of Th1 cells such as TNF- } \alpha \text { lead to } \\
\text { endothelial dysfunction and consequently cause T-cell } \\
\text { movement to atherosclerotic plaques. IL-17 contributes } \\
\text { to vascular and systemic inflammation in experimental } \\
\text { atherosclerosis in murine models [104]. } \\
\text { Modulating the Th-17/IL-17 pathway might play a key role } \\
\text { in the progression of coronary atherosclerosis [105]. }\end{array}$ \\
\hline Heart failure & $\begin{array}{l}\text { Increased serum/plasma levels of TNF- } \alpha \text { and IL-6 promote } \\
\text { metabolic syndrome [106]. } \\
\text { TNF- } \alpha \text { levels show a linear relationship with prognosis } \\
{[107] .} \\
\text { Congestive heart failure is inversely associated with IL-6 } \\
\text { levels [108]. }\end{array}$ \\
\hline $\begin{array}{l}\text { TNF- } \alpha \text { exacerbates hepatic insulin resistance, resulting in } \\
\text { increased free fatty acid synthesis and decreased free fatty } \\
\text { acid oxidations, thereby promoting hepatic steatosis. Thus, } \\
\text { the relationship between non-alcoholic fatty liver disease and } \\
\text { diabetes mellitus type 2 is complex and bidirectional [109]. }\end{array}$ \\
\hline
\end{tabular}

In the vascular wall, oxLDL, cholesterol, and nicotine have the ability to induce IL-23 secretion by DCs. Abbas et al. [115] and Di Cesare et al. [116] reported a considerable associated between oxLDL and IL-23. In dyslipidaemia, oxLDL binding to LOX-1 could induce endothelial dysfunction, macrophage foam cell formation, and smooth muscle cell migration and proliferation. Additionally, the relationships among the oxLDL receptor, IL-23, and LOX-1 still need to be studied.

Glycoprotein acetylation (GlycA) is a recent biomarker for systemic inflammation that can predict $\mathrm{CV}$ events, risk of serious infection, or type 2 diabetes [117]. In addition, it has shown good results in the assessment of the pathology or in the response to treatments. To assess its use as a biomarker in psoriasis, a study by Joshi et al. [118] included patients with mild to moderate psoriasis and control patients, for a total of 412 participants. They observed that there is a correlation between GlycA and high sensitivity C-reactive protein (hsPCR) in patients with psoriasis. In addition, there is also a correlation between GlycA and the severity of psoriasis. There are other risk factors that correlate with GlycA in psoriasis, such as BMI, 
waist-hip ratio, metabolic syndrome, HDL cholesterol, and LDL cholesterol. GlycA is associated with vascular inflammation (LV) and coronary artery disease (CAD). However, CAD is not associated with hsPCR in patients with psoriasis, but in controls. This indicates that GlycA is associated with cardiovascular disease (CVD) independently of traditional risk factors. After treatment with anti-TNF therapy in a group of 16 patients with psoriasis, GlycA levels were observed to have decreased, compared with baseline; however, this decrease was not the same as that of hsPCR levels which was statistically non-significant. In the treated patients, aortic VI also decreased.

Each of the patients studied by Montaudié et al. [119] had a comorbidity, and $45 \%$ had two or more. When treatment with biological agents (infliximab, adalimumab, etanercept and ustekinumab) was used, a statistically significant decrease was observed only for the inflammatory parameters (CRP, $\mathrm{P}=0.004)$ and the erythrocyte sedimentation rate (ESR, $\mathrm{P}=0.002$ ).

In a study by Jiang et al. [120], adipokine imbalance was associated with chronic inflammatory state and insulin resistance. Psoriasis seems to be an independent risk factor of CV complications. Biological therapy including efalizumab and alefacept, primarily disrupt the activation and migration of $\mathrm{T}$ cells, whereas agents like infliximab, etanercept, and adalimumab target TNF-a. Recently, agents, which target the $\mathrm{p} 40$ subunit shared by both IL-12 and IL-23, have been developed, as well as new anti-IL-17 agents and anti-IL23p19 agents, was found to improve endothelial function and reduce carotid vascular remodelling $[121,122]$.

Several authors, such as Späh et al. [123] have demonstrated that antirheumatic drugs, such as methotrexate, reduce the risk of cardiovascular disease in patients with psoriasis. Other biological therapies used in the treatment of psoriasis such as etanercept, infliximab, and adalimumab, could have a beneficial effect on cardiovascular function in addition to reducing the levels of systemic markers of inflammation, such as ESR and CRP. [124]. Other authors as Ridker et al. ( CIRT study) no benefit founded with low-dose of methotrexate for prevention the atherosclerotic events or CVD [125]

However, new therapeutic targets are controversial, since recent studies on anti-IL12/23 and anti-IL17 suggested that they could increase CVD risk in psoriatic patients. Rungapiromnan et al. [126] compiled data from the Cochrane Library, MEDLINE, Embase, U.S. Food and Drug Administration, European Medicines Agency, pharmaceutical companies, and five clinical trial registers. They found that there were no adverse effects during the short, randomized, and controlled clinical trials

Finally, a study conducted by Lee et al. [127] with 60,028 patients with psoriasis were included and treated with Ustekinumab (Us) vs TNF Inhibitor (TNFi). No substantially different risk of incident of atrial fibrillation and major adverse cardiovascular events after initiation of Us vs TNFi was observed in this study

The main biomarkers of inflammation involved on diagnose, prognosis and treatment in patients with psoriasis and cardiovascular risk factors, are collated in Table $2[12,17,49,57,64,65,67-84,86-91$, 92-94, 99, 114-120].

\section{Conclusions}

The association between psoriasis and cardiovascular risk factors has been recently demonstrated by several groups, especially in young patients with severe forms of psoriasis. This association implies that psoriasis should not be exclusively considered as a cutaneous or joint disease, but rather as a chronic inflammatory disease with systemic involvement. Thus, in addition to specifically treating cutaneous symptoms in patients with psoriasis, managing classic risk factors involved in atherogenesis is paramount.

PCPs are in an important position to detect and respond to early indicators of CVD risk and comorbidities in their patients, they working collaboratively with dermatology health professionals and other specialists, PCPs can facilitate communication about the patient's treatment preferences and personalized for each patient to optimize treatment in each case. Moreover, as mechanisms involved in psoriasis and CVD are further elucidated, future therapeutic strategies may involve inhibition of pro-inflammatory cytokines that are involved in both diseases.

Since psoriasis carries a risk of developing CVD that is probably due to systemic inflammation, there is a need for new prognostic, diagnostic, and treatment biomarkers. The purpose of these biomarkers is to improve diagnosis for intervention by reducing inflammation, which could reduce or eliminate CVD risk in psoriatic patients.

These biomarkers should be used particularly in primary care to detect and filter patients with psoriasis that have elevated risk of developing CVD.

Therefore, these biomarkers allow for rapid detection of high-risk psoriasis patients for myocardial infarction and heart failure to avoid complications. Since detection of these biomarkers is highly sensitive and specific, it should be routinely implemented in healthcare systems around the world.

\section{Conflicts of Interest}

The authors declare no potential competing interests with respect to the research, authorship and/or publication of this article.

\section{Funding Statement}

No funding was received.

\section{Abbrevations}

CV: Cardiovascular

CRP: C-reactive protein

IFN: Interferon

IL: Interleukin

LL37: Cathelicidin

PMN: Polymorphonuclear neutrophil

S-100: S-100 proteins

Th: T-helper cells 
Carmen Rodríguez-Cerdeira (2020) Measurement and Clinical Significance of Novel Inflammatory Biomarkers in Patients with Psoriasis and Cardiovascular Risk Factors for the Primary Care Practitioner

Table 2. Biomarkers of inflammation in patients with psoriasis and cardiovascular risk factors

\begin{tabular}{|c|c|c|}
\hline TYPE & BIOMARKERS & REFERENCES \\
\hline \multirow[t]{14}{*}{ PROGNOSIS } & HLA antigens (A30, B50, Cw6 and DR7.20) & [64] \\
\hline & Metabolic Syndrome & [83] \\
\hline & Oxidation lipid mediators (OxLp(a), OxHDL, OxLDL) & [57] \\
\hline & Monocytes (CD14+, CD16+) // Monocytes (CD14++, CD162) & [67] \\
\hline & Fluorodeoxyglucose (FDG) & [49] \\
\hline & S100A8/A9 & [49] \\
\hline & Downregulation of CD16 and CD62L & [49] \\
\hline & Microparticles present in the atherosclerotic plaque breakdown & [68] \\
\hline & Homocysteine & {$[69,70]$} \\
\hline & Tetrahydrofolate reductase (MTHFR) & [71] \\
\hline & Cytokines (CRP, IL-6, IL-10) & {$[6572,75]$} \\
\hline & AmygA & {$[73,74]$} \\
\hline & Fetuin-A // Carotid intima-media thickness (CIMT) & {$[76,77]$} \\
\hline & Adiponectin, resistin, leptin, vaspin & {$[17,78,79]$} \\
\hline \multirow[t]{20}{*}{ DIAGNOSIS } & Chemerin & {$[80,81]$} \\
\hline & CD15+ neutrofils & [80] \\
\hline & CD123+/BDCA-2+/ChemR23+ plasmatoid dendritic cells & [80] \\
\hline & CRP & {$[12,82,83]$} \\
\hline & Soluble CD40 ligand & [12] \\
\hline & Fetuin-A // Carotid intima-media thickness (CIMT) & {$[12,90]$} \\
\hline & YKL-40 & [12] \\
\hline & GlycA & [12] \\
\hline & Complement $\mathrm{C} 3$ & [12] \\
\hline & Human matrix Gla protein & [12] \\
\hline & Adiponectin, resistin, leptin & {$[82,83,87,88]$} \\
\hline & Lymphocytes (Th1, Th17) & [82] \\
\hline & Lp-PLA2 & {$[83,84]$} \\
\hline & Cytokines (IL-22, IL-17, IL-23, IL- 8, TNF- $\alpha$, EGF) & [86] \\
\hline & oxLDL/LDL ratio & [89] \\
\hline & Advanced oxidation protein products (AOPPs) & [90] \\
\hline & Visfatin & [90] \\
\hline & FTO allele (rs9939609) & [91] \\
\hline & Vitamin D & {$[92,93]$} \\
\hline & The major allele T of rs4597342 -ITGAM (only female) & [94] \\
\hline \multirow[t]{7}{*}{ TREATMENT } & Interlekines (IL-12, IL-23, IL-17) & $\begin{array}{r}{[99,110,111,115} \\
116]\end{array}$ \\
\hline & Oxidation lipid mediators (OxHDL, OxLDL) & {$[114,115,116]$} \\
\hline & LOX-1 & {$[114,115,116]$} \\
\hline & GlycA & [117] \\
\hline & CRP & [118] \\
\hline & Carotid intima-media thickness (CIMT) & [119] \\
\hline & ESR, CRP & [120] \\
\hline
\end{tabular}


Carmen Rodríguez-Cerdeira (2020) Measurement and Clinical Significance of Novel Inflammatory Biomarkers in Patients with Psoriasis and Cardiovascular Risk Factors for the Primary Care Practitioner

TGF- $\beta$ : Transforming growth factor-beta

Tn: Naïve T lymphocyte

TNF: Tumor necrosis factor

CCL: CC chemokine ligands

CXCL: Chemokine (C-X-C motif) ligand

$\beta$-DEF: $\beta$-defensins

KC: Keratinocyte

mDC: Myeloid dendritic cell

pDC: plasmacytoid Dendritic Cells

LCN2: Antimicrobial peptide

NKT: Natural killer T cell

TSLP: Thymic stromal lymphopoietin

NO: Nitric oxide

pDC: Plasmacytoid dendritic cell

TSLP: Thymic stromal lymphopoietin

\section{References}

1. Gudjonsson JE, Elder JT. Psoriasis. (2012) In: Goldsmith LA, Katz SI, editors. Fitzpatrick's dermatology in general medicine. McGraw-Hill; p. 169-193.

2. van de Kerkhof PCM, Nestle FO. (2012) Psoriasis. In: Bolognia JL, Jorizzo JL, editors. Dermatology. Elsevier; p. 135-156.

3. Tampa M, Sarbu MI, MitranMI, Mitran CI, Matei C, Georgescu SR. (2018) The pathophysiological mechanisms and the quest for biomarkers in psoriasis, a stressrelated skin disease. Dis Markers. 2018: 5823684. [Crossref]

4. Surcel M, Huica R, Constantin C, Ursaciuc C, Neagu M. (2017) Biomarkers insights in psoriasis-regulatory cytokines. Current Biomarkers. 7(1): 3-11.

5. Benson JM, Sachs CW, Treacy G, Zhou H, Pendley CE, Brodmerkel CM, et al. (2011) Therapeutic targeting of the IL-12/23 pathways: generation and characterization of ustekinumab. Nat Biotechnol. 29: 615-624.

6. Fernández-Armenteros JM, Gómez-Arbonés X, Buti-Soler, Betriu-Bars A, Sanmartin-Novell V, Ortega-Bravo M, et al. (2019) Psoriasis, metabolic syndrome and cardiovascular risk factors. A population-based study. J Eur Acad Dermatol Venereol. 33: 128-135. [Crossref]

7. Kimball AB, Guerin A, Latremouille-Viau D, Yu AP, Gupta S, Bao Y, et al. (2010) Coronary heart disease and stroke risk in patients with psoriasis: retrospective analysis. Am J Med. 123: 350-357. [Crossref]

8. Hu SC, Yuan SF, Chen GS, Tu HP. (2019) Increased incidence of ischaemic heart disease and cerebrovascular disease in psoriasis patients with depression: a nationwide retrospective cohort study. J Eur Acad Dermatol Venereol. 33(8): 15471554. [Crossref]

9. Babino G, Fulgione E, Giorgio CM, Agozzino M, Alfano R, Argenziano G. (2019) Efficacy and safety of secukinumab in a psoriatic patient affected by comorbid metabolic disorders. Dermatol Ther. 32(3): e12858. [Crossref]

10. Svecova D, Lubell MW, Casset-Semanaz F, Mackenzie H, Grenningloh R, Krueger JG. (2019) A randomized, double-blind, placebo-controlled phase 1 study of multiple ascending doses of subcutaneous M1095, an anti-interleukin 17A/F nanobody, in moderate-to-severe psoriasis. J Am Acad Dermatol. 81(1): 196-203. [Crossref]

11. Boehncke S, Thaci D, Beschmann H, Ludwig RJ, Ackermann H, Badenhoop K, et al. (2007) Psoriasis patients show signs of insulin resistance. Br J Dermatol. 157(6): 1249-51.

12. Hu SC, Lan CE. (2017) Psoriasis and cardiovascular comorbidities: focusing on severe vascular events, cardiovascular risk factors and implications for treatment. Int J Mol Sci. 18(10). [Crossref]

13. Tablazon IL, Al-Dabagh A, Davis SA, Feldman SR. (2013) Risk of cardiovascular disorders in psoriasis patients: current and future. Am J Clin Dermatol. 14(1): 1-7. [Crossref]

14. Alexandroff AB, Pauriah M, Camp RD, Lang CC, Struthers AD, Armstrong DJ. (2009) More than skin deep: atherosclerosis as a systemic manifestation of psoriasis. Br J Dermatol. 161(1): 1-7. [Crossref]

15. Schäkel K, Schön MP, Ghoreschi K. (2016) Pahogenesis of psoriasis. Hautarzt. 67(6): 422-31. [Crossref]
16. Boehncke WH. (2018) Systemic Inflammation and cardiovascular comorbidity in psoriasis patients: causes and consequences. Front Immunol. 9: 579. [Crossref]

17. Bavoso NC, Pinto JM, Soares MMS, Diniz MDS, Teixeira Júnior AL. (2019) Psoriasis in obesity: comparison of serum levels of leptin and adiponectin in obese subjects - cases and controls. An Bras Dermatol. 94(2): 192-197. [Crossref]

18. Gil-Guillén V, Orozco-Beltrán D, Maiques-Galán A, Aznar-Vicente J, Navarro J, Cea-Calvo L, et al. (2007) Agreement between REGICOR and SCORE scales in identifying high cardiovascular risk in the Spanish population. Rev Esp Cardiol. 60(10): 1042-50.

19. Khera AV, Demler OV, Adelman SJ, Collins HL, Glynn RJ, Ridker PM, et al. (2017) Cholesterol efflux capacity, high-density lipoprotein particle number, and incident cardiovascular events: an analysis from the JUPITER trial (justification for the use of statins in prevention: an intervention trial evaluating rosuvastatin). Circulation. 135(25): 2494-2504. [Crossref]

20. Ruiz-Villaverde G, López de la Torre-Casares M, Sánchez-Cano D, VillaverdeGutiérrez C. (2006) Comparison of the Score and Framingham-DORICA models to estimate the cardiovascular risk in a cohort of hypertensive patients from southern Spain. Med Clin (Barc). 127(8): 314-5.

21. Topel ML, Shen J, Morris AA, Al Mheid I, Sher S, Dunbar SB, et al. (2018) Comparisons of the Framingham and pooled cohort equation risk scores for detecting subclinical vascular disease in blacks versus whites. Am J Cardiol. 121(5): 564-569. [Crossref]

22. Puig L. (2012) Cardiovascular risk and psoriasis: the role of biologic therapy. Actas Dermosifiliogr. 103(10): 853-62. [Crossref]

23. QRISK ${ }^{\circledR} 3-2018$, risk calculator, already have a diagnosis of coronary heart disease (including angina or heart attack). https://qrisk.org/three/, 2018 (accessed 24 June 2019).

24. Hippisley-Cox J, Coupland C, Vinogradova Y, Robson J, Brindle P. (2008) Performance of the QRISK cardiovascular risk prediction algorithm in an independent UK sample of patients from general practice: a validation study. Heart. 94(1): 34-9. [Crossref]

25. Daudén E, Castañeda S, Suárez C, García-Campayo J, Blasco AJ, Aguilar MD. (2012) Integrated approach to comorbidity in patients with psoriasis. Actas Dermosifiliogr. 103 Suppl 1: 1-64.

26. Cea-Calvo L, Vanaclocha F, Belinchón I, Rincón Ó, Juliá B, Puig L. (2016) Underdiagnosis of cardiovascular risk factors in outpatients with psoriasis followed at hospital dermatology offices: The PSO-RISK study. Acta Derm Venereol. 96(7): 972-973.

27. Willard-Grace R, Chen EH, Hessler D, DeVore D, Prado C, Bodenheimer T. (2015) Health coaching by medical assistants to improve control of diabetes, hypertension, and hyperlipidemia in low-income patients: a randomized controlled trial. Ann Fam Med. 13(2): 130-8. [Crossref]

28. Moore KJ, Sheedy FJ, Fisher EA. (2013) Macrophages in atherosclerosis: a dynamic balance. Nat Rev Immunol. 13(10): 709-21. [Crossref]

29. Shin DW, Cho J, Yang HK, Park JH, Lee H, Kim H, et al. (2014) Impact of continuity of care on mortality and health care costs: a nationwide cohort study in Korea. Ann Fam Med. 12(6): 534-41. [Crossref]

30. Rafieian-Kopaei M, Setorki M, Doudi M, Baradaran A, Nasri H. (2014) Atherosclerosis: process, indicators, risk factors and new hopes. Int J Prev Med. 5(8): 927-46. [Crossref]

31. Balak DM, Hajdarbegovic E. (2017) Drug-induced psoriasis: clinical perspectives. Psoriasis (Auckl). 7: 87-94. [Crossref]

32. Milaniuk S, Pietrzak A, Mosiewicz B, Mosiewicz J, Reich K. (2015) Influence of psoriasis on circulatory system function assessed in echocardiography. Arch Dermatol Res. 307(10): 855-61. [Crossref]

33. Dattilo G, Imbalzano E, Casale M, Guarneri C, Borgia F, Mondello S, et al. (2018) Psoriasis and cardiovascular risk: correlation between psoriasis and cardiovascular functional indices. Angiology. 69(1): 31-37. [Crossref]

34. Sutton-Tyrrell K, Najjar SS, Boudreau RM, Venkitachalam L, Kupelian V, Simonsick EM, et al. (2005) Elevated aortic pulse wave velocity, a marker of arterial stiffness, predicts cardio-vascular events in well-functioning older adults. Circulation. 111(25): 3384-90. [Crossref]

35. Ardic I, Kaya MG, Yarlioglues M, Karadag Z, Dogan A, Yildiz H, et al. (2010) Impaired aortic elastic properties in normotensive patients with psoriasis. Blood Press. 19(6): 351-8

36. Gorga E, Scodro M, Valentini F, D’Ortona R, Arisi M, Sciatti E, et al. (2018) Echocardiographic evaluation of diastolic dysfunction in young and healthy patients with psoriasis: A case-control study. Monaldi Arch Chest Dis. 88(3): 934.

37. Bulbul Sen B, Atci N, Rifaioglu EN, Ekiz O, Kartal I, Buyukkaya E, et al. (2013) Increased epicardial fat tissue is a marker of subclinical atherosclerosis in patients with psoriasis. Br J Dermatol. 169(5): 1081-6. [Crossref]

38. Gisondi P, Ferrazzi A, Girolomoni G. (2010) Metabolic comorbidities and psoriasis. Acta Dermatovenerol Croat. 18(4): 297-304. [Crossref] 
Carmen Rodríguez-Cerdeira (2020) Measurement and Clinical Significance of Novel Inflammatory Biomarkers in Patients with Psoriasis and Cardiovascular Risk Factors for the Primary Care Practitioner

39. Tang K, Lin J, Ji X, Lin T, Sun D, Zheng X, et al. (2019) Non-alcoholic fatty liver disease with reduced myocardial FDG uptake is associated with coronary atherosclerosis. J Nucl Cardiol. 2019.

40. Schiffrin EL. (2002) Beyond blood pressure: the endothelium and atherosclerosis progression. Am J Hypertens. 15(10 Pt 2): 115S-122S. [Crossref]

41. El-Mongy S, Fathy H, Abdelaziz A, Omran E, George S, Neseem N, et al. (2010) Subclinical atherosclerosis in patients with chronic psoriasis: a potential association. J Eur Acad Dermatol Venereol. 24(6): 661-6. [Crossref]

42. Biyik I, Narin A, Bozok MA, Ergene O. (2006) Echocardiographic and clinical abnormalities in patients with psoriasis. J Int Med Res. 34(6): 632-9. [Crossref]

43. Goyal A, Dey AK, Chaturvedi A, Elnabawi YA, Aberra TM, Chung JH et al. (2018) Chronic stress-related neural activity associates with subclinical cardiovascular disease in psoriasis: a prospective cohort study. JACC Cardiovasc Imaging. pii: S1936-878X(18)30920-3. [Crossref]

44. Tawakol A, Ishai A, Takx RA, Figueroa AL, Ali A, Kaiser Y et al. (2017) Relation between resting amygdalar activity and cardiovascular events: a longitudinal and cohort study. Lancet. 389(10071): 834-845. [Crossref]

45. Shiba M, Kato T, Izumi T, Miyamoto S, Nakane E, Haruna T, et al. (2019) Risk of myocardial infarction in patients with psoriasis: a cross-sectional patient-population study in a Japanese hospital. J Cardiol. 73(4): 276-279. [Crossref]

46. Polic MV, Miskulin M, Smolic M, Kralik K, Miskulin I, Berkovic MC, et al. (2018) Psoriasis severity - A risk factor of insulin resistance independent of metabolic syndrome. Int J Environ Res Public Health. 15(7). [Crossref]

47. Prodanovich S, Kirsner RS, Kravetz JD, Ma F, Martinez L, Federman DG. (2009) Association of psoriasis with coronary artery, cerebrovascular, and peripheral vascular diseases and mortality. Arch Dermatol. 145(6): 700-3.

48. Eder L, Chandran V, Gladman DD. (2014) The Framingham Risk Score underestimates the extent of subclinical atherosclerosis in patients with psoriatic disease. Ann Rheum Dis. 73(11): 1990-6. [Crossref]

49. Naik HB, Natarajan B, Stansky E, Ahlman MA, Teague H, Salahuddin T, et al. (2015) The severity of psoriasis associates with aortic vascular inflammation detected by FDG PET/CT and neutrophil activation in a prospective observational study. Arterioscler Thromb Vasc Biol. 35(12): 2667-76. [Crossref]

50. Prey S, Paul C, Bronsard V, Puzenat E, Gourraud PA, Aractingi S, et al. (2010) Cardiovascular risk factors in patients with plaque psoriasis: a systematic review of epidemiological studies. J Eur Acad Dermatol Venereol. 24 Suppl 2: 23-30. [Crossref]

51. Qureshi AA, Choi HK, Setty AR, Curhan GC. (2009) Psoriasis and the risk of diabetes and hypertension: a prospective study of US female nurses. Arch Dermatol. 145(4): 379-82. [Crossref]

52. Brauchli YB, Jick SS, Meier CR. (2008) Psoriasis and the risk of incident diabetes mellitus: a population-based study. Br J Dermatol. 159(6): 1331-7. [Crossref]

53. Herron MD, Hinckley M, Hoffman MS, Papenfuss J, Hansen CB, Callis KP, et al. (2005) Impact of obesity and smoking on psoriasis presentation and management. Arch Dermatol. 141(12): 1527-34. [Crossref]

54. Uyar B, Akyildiz M, Solak A, Genc B, Saklamaz A, et al. (2015) Relationship between serum Fetuin-A levels and carotid intima-media thickness in Turkish patients with mild to moderate psoriasis. A case-control study. Acta Dermatovenerol Croat. 23(3): 171-7. [Crossref]

55. Rosa DJ, Machado RF, Matias FA, Cedrim SD, Noronha FL, Gaburri D, et al. (2012) Influence of severity of the cutaneous manifestations and age on the prevalence of several cardiovascular risk factors in patients with psoriasis. J Eur Acad Dermatol Venereol. 26(3): 348-53.

56. Gisondi P, Farina S, Giordano MV, Girolomoni G. (2010) Usefulness of the Framingham risk store in patients with chronic psoriasis. Am J Cardiol. 106(12): 1754-7. [Crossref]

57. Sorokin AV, Kotani K, Elnabawi YA, Dey AK, Sajja AP, Yamada S, et al. (2018) Association between oxidation-modified lipoproteins and coronary plaque in psoriasis. Circ Res. 123(11): 1244-1254. [Crossref]

58. Myśliwiec H, Baran A, Harasim-Symbor E, Choromańska B, Myśliwiec P, Milewska AJ, et al. (2017) Increase in circulating sphingosine-1-phosphate and decrease in ceramide levels in psoriatic patients. Arch Dermatol Res. 309(2): 79-86. [Crossref]

59. Blegvad C, Nybo Andersen AM, Adam A, Zachariae C, Skov L. (2019) Psoriasis as a predictor of cardiometabolic comorbidity in women: a study based on the Danish national birth cohort Acta Derm Venereol. 99(3): 274-278. [Crossref]

60. Pietrzak A, Czuczwar P, Mosiewicz J, Paszkowski T, Chodorowska G, Bartosinska J, et al. (2015) Cardiovascular disease in psoriatic post-menopausal women. $J$ Eur Acad Dermatol Venereol. 29(6): 1231-4.

61. Li WQ, Cho E, Weinstock MA, Mashfiq H, Qureshi AA. (2016) Epidemiological assessments of skin outcomes in the Nurses' Health Studies. Am J Public Health. 106(9): 1677-83. [Crossref]
62. Li W, Han J, Hu FB, Curhan GC, Qureshi AA. (2012) Psoriasis and risk of type 2 diabetes among women and men in the United States: a population-based cohort study. J Invest Dermatol. 132(2): 291-8. [Crossref]

63. Li WQ, Han JL, Manson JE, Rimm EB, Rexrode KM, Curhan GC, et al. (2012) Psoriasis and risk of nonfatal cardiovascular disease in U.S. women: a cohort study. Br J Dermatol. 166(4): 811-8. [Crossref]

64. Kundakçi N, Oskay T, Olmez U, Tutkak H, Gürgey E. (2002) Association of psoriasis vulgaris with HLA class I and class II antigens in the Turkish population, according to the age at onset. Int J Dermatol. 41(6): 345-8. [Crossref]

65. Wongpiyabovorn J, Hirankarn N, Ruchusatsawat K, Yooyongsatit S, Asawanonda P, Poovorawan Y. (2008) Association of the interleukin-10 distal promoter (-2763A/ C) polymorphism with late-onset psoriasis. Clin Exp Dermatol. 33(2): 186-9.

66. Dinić M, Zečević RD, Hajduković Z, Mijušković M, Đurić P, Jović Z. (2016) Psoriasis is the independent factor for early atherosclerosis: A prospective study of cardiometabolic risk profile. Vojnosanit Pregl. 73(12): 1094-1101. [Crossref]

67. Golden JB, Groft SG, Squeri MV, Debanne SM, Ward NL, McCormick TS, et al. (2015) Chronic psoriatic skin inflammation leads to increased monocyte adhesion and aggregation. J Immunol. 195(5): 2006-18.

68. Ryan C, Kirby B. (2015) Psoriasis is a systemic disease with multiple cardiovascular and metabolic comorbidities. Dermatol Clin. 33(1): 41-55. [Crossref]

69. Tinelli C, Di Pino A, (2019) Ficulle E, Marcelli S, Feligioni M. Hyperhomocysteinemia as a risk factor and potential nutraceutical target for certain pathologies. Front Nutr. 6: 49. [Crossref]

70. Wang WM, Jin HZ. (2017) Homocysteine: A potential common route for cardiovascular risk and DNA methylation in psoriasis. Chin Med J (Engl). 130(16): 1980-1986. [Crossref]

71. Qi JH, Qi JH, Shi N, Chen YJ, Nie G. (2015) Association between MTHFR 677C/T polymorphism and psoriasis risk: A metaanalysis. Genet Mol Res. 14(2): 3869-76. [Crossref]

72. Kaur S, Kingo K, Zilmer M. (2017) Psoriasis and cardiovascular risk-do promising new biomarkers have clinical impact? Mediators Inflamm. 2017: 7279818. [Crossref]

73. Johnson TV, Abbasi A, Master VA. (2013) Systematic review of the evidence of a relationship between chronic psychosocial stress and C-reactive protein. Mol Diagn Ther: 17(3): 147-64. [Crossref]

74. Paschoal RS, Silva DA, Cardili RN, Souza CDS. (2018) Metabolic syndrome, C-reactive protein and cardiovascular risk in psoriasis patients: a cross-sectional study. An Bras Dermatol. 93(2): 222-228. [Crossref]

75. Uaratanawong R, Uaratanawong S, Chunhasewee C, Chawvavanich P. (2016) High sensitivity C-Reactive protein level and psoriasis severity in Thai patients. J Med Assoc Thai. 99(9): 1039-45[Crossref]

76. Yiu KH, Yeung CK, Zhao CT, Chan JC, Siu CW, Tam S, et al. (2013) Prevalence and extent of subclinical atherosclerosis in patients with psoriasis. J Intern Med. 273(3): 273-82.

77. Ix JH1, Barrett-Connor E, Wassel CL, Cummins K, Bergstrom J, Daniels LB, et al. (2011) The associations of fetuin-A with subclinical cardiovascular disease in community-dwelling persons: The Rancho Bernardo Study. $J$ Am Coll Cardiol. 58(23): 2372-9. [Crossref]

78. Yazıcı D, Yavuz D, Öğünç AV, Sirikçi Ö, Toprak A, Deyneli O, et al. (2012) Serum adipokine levels in type 1 diabetic patients: association with carotid intima media thickness. Metab Syndr Relat Disord. 10(1): 26-31.

79. Ataseven A, Kesli R. (2016) Novel inflammatory markers in psoriasis vulgaris: vaspin, vascular adhesion protein-1 (VAP-1), and YKL-40. G Ital Dermatol Venereol. 151(3): 244-50. [Crossref]

80. Nakajima H, Nakajima K, Tarutani M, Sano S. (2013) Clear association between serum levels of adipokines and T-helper 17-related cytokines in patients with psoriasis. Clin Exp Dermatol. 38(1): 66-70. [Crossref]

81. Albanesi C, Scarponi C, Pallotta S, Daniele R, Bosisio D, Madonna S, et al (2009) Chemerin expression marks early psoriatic skin lesions and correlates with plasmacytoid dendritic cell recruitment. J Exp Med. 16;206(1): 249-58. [Crossref]

82. Furue M, Tsuji G, Chiba T, Kadono T. (2017) Cardiovascular and Metabolic diseases comorbid with psoriasis: beyond the skin. Intern Med. 56(13): 1613-1619. [Crossref]

83. Vachatova S, Andrys C, Krejsek J, Salavec M, Ettler K, Rehacek V, et al. (2016) Metabolic syndrome and selective inflammatory markers in psoriatic patients. $J$ Immunol Res. 2016: 5380792. [Crossref]

84. Kiluk P, Baran A, Świderska M, Maciaszek M, Flisiak I. (2019) Lp- PLA2 as a promising predictor of comorbidities in patients with severe psoriasis. J Dermatolog Treat. 1-7. [Crossref]

85. Wang Q, McCormick TS, Ward NL, Cooper KD, Conic R, Xu R. (2018) Combining mechanism-based prediction with patient-based profiling for psoriasis metabolomics biomarker discovery. AMIA Annu Symp Proc. 2017: 1734-1743. [Crossref] 
Carmen Rodríguez-Cerdeira (2020) Measurement and Clinical Significance of Novel Inflammatory Biomarkers in Patients with Psoriasis and Cardiovascular Risk Factors for the Primary Care Practitioner

86. Coimbra S, Oliveira H, Reis F, Belo L, Rocha S, Quintanilha A, et al. (2010) Interleukin (IL)-22, IL-17, IL-23, IL-8, vascular endothelial growth factor and tumour necrosis factor- $\alpha$ levels in patients with psoriasis before, during and after psoralen-ultraviolet A and narrowband ultraviolet B therapy. Br J Dermatol. 163(6): $1282-90$.

87. Ellulu MS, Patimah I, Khaza'ai H, Rahmat A, Abed Y. (2017) Obesity and inflammation: the linking mechanism and the complications. Arch Med Sci. 13(4): 851-863. [Crossref]

88. Rodríguez-Cerdeira C, Cordeiro-Rodríguez M, Carnero-Gregorio M, LópezBarcenas A, Martínez-Herrera E, Fabbrocini G, et al. (2019) Biomarkers of inflammation in obesity-psoriatic patients. Mediators Inflamm. 2019: 7353420. [Crossref]

89. Asha K, Singal A, Sharma SB, Arora VK, Aggarwal A. (2017) Dyslipidaemia \& oxidative stress in patients of psoriasis: emerging cardiovascular risk factors. Indian J Med Res. 146(6): 708-713. [Crossref]

90. Haberka M, Bańska-Kisiel K, Bergler-Czop B, Biedroń M, Brzezińska-Wcisło L, Okopien B, et al. (2018) Mild to moderate psoriasis is associated with oxidative stress, subclinical atherosclerosis, and endothelial dysfunction. Pol Arch Intern Med. 128(7-8): 434-439. [Crossref]

91. Tupikowska-Marzec M, Kolačkov K, Zdrojowy-Wełna A, Słoka NK, Szepietowski JC, Maj J. (2019) The Influence of FTO polymorphism rs 9939609 on obesity, some clinical features, and disturbance of carbohydrate metabolism in patients with psoriasis. Biomed Res Int. 2019: 7304345. [Crossref]

92. Barrea L, Savanelli MC, Di Somma C, Napolitano M, Megna M, Colao A, et al. (2017) Vitamin D and its role in psoriasis: An overview of the dermatologist and nutritionist. Rev Endocr Metab Disord. 18(2): 195-205. [Crossref]

93. Herrmann M, Farrell CL, Pusceddu I, Fabregat-Cabello N, Cavalier E. (2017) Assessment of vitamin D status - a changing landscape. Clin Chem Lab Med. 55(1): 3-26. [Crossref]

94. Hruska P, Kuruczova D, Vasku V, Bienertova-Vasku J. (2019) MiR-21 binding site SNP within ITGAM associated with psoriasis susceptibility in women. PLoS One. 14(6): e0218323. [Crossref]

95. Shi D, Zhong Z, Xu R, Li B, Li J, Habib U, et al. (2019) Association of ITGAX and ITGAM gene polymorphisms with susceptibility to IgA nephropathy. J Hum Genet. 64(9): 927-935.

96. Törn C, Liu X, Hagopian W, Lernmark Å, Simell O, Rewers M, et al. (2016) Complement gene variants in relation to autoantibodies to beta cell specific antigens and type 1 diabetes in the TEDDY Study. Sci Rep. 6: 27887. [Crossref]

97. Gulliver WP, Randell S, Gulliver S, Connors S, Bachelez H, MacDonald D, et al. (2016) Do biologics protect patients with psoriasis from myocardial infarction? A retrospective cohort. J Cutan Med Surg. 20(6): 536-541. [Crossref]

98. Caiazzo G, Fabbrocini G, Di Caprio R, Raimondo A, Scala E, Balato N, et al. (2018) Psoriasis, cardiovascular events, and biologics: lights and shadows. Front Immunol. 9: 1668. [Crossref]

99. Krueger GG, Langley RG, Leonardi C, Yeilding N, Guzzo C, Wang Y, et al. (2007) A human interleukin-12/23 monoclonal antibody for the treatment of psoriasis. $N$ Engl J Med. 356(6): 580-92. [Crossref]

100. Popko K, Gorska E, Stelmaszczyk-Emmel A, Plywaczewski R, Stoklosa A, Gorecka D, et al. (2010) Proinflammatory cytokines Il-6 and TNF- $\alpha$ and the development of inflammation in obese subjects. Eur J Med Res. 15 Suppl 2: 120-2. [Crossref]

101. Kaplanski G. (2018) Interleukin-18: Biological properties and role in disease pathogenesis. Immunol Rev. 281(1): 138-153. [Crossref]

102. Alipourfard I, Datukishvili N, Mikeladze D. (2019) TNF- $\alpha$ downregulation modifies insulin receptor substrate 1 (IRS-1) in metabolic signaling of diabetic insulin-resistant hepatocytes. Mediators Inflamm. 2019: 3560819. [Crossref]

103. Zhang C. (2008) The role of inflammatory cytokines in endothelial dysfunction. Basic Res Cardiol. 103(5): 398-406. [Crossref]

104. Erbel C, Akhavanpoor M, Okuyucu D, Wangler S, Dietz A, Zhao L, et al. (2014) IL-17A influences essential functions of the monocyte/macrophage lineage and is involved in advanced murine and human atherosclerosis. J Immunol. 193(9): 4344-55. [Crossref]

105. Cimmino G, Ciuffreda LP, Ciccarelli G, Calabrò P, Ferraiolo FA, Rivellino A, et al. (2017) Upregulation of TH/IL-17 pathway-related genes in human coronary endothelial cells stimulated with serum of patients with acute coronary syndromes. Front Cardiovasc Med. 4: 1. [Crossref]

106. Mohammadi M, Gozashti MH, Aghadavood M, Mehdizadeh MR, Hayatbakhsh MM. (2017) Clinical significance of serum IL- 6 and TNF- $\alpha$ levels in patients with metabolic syndrome. Rep Biochem Mol Biol. 6(1): 74-79. [Crossref]

107. Heberto Herrera Garza E, Herrera Garza JL, Rodríguez González H, Treviño Treviño A, Ibarra Flores M, Torre Amione G. (2002) Importance of tumor necrosis factor-alpha in the pathogenesis of heart failure. Rev Esp Cardiol. 55(1): 61-6.

108. Liu M, Chen J, Huang D, Ke J, Wu W. (2014) A meta-analysis of proinflammatory cytokines in chronic heart failure. Heart Asia. 6(1): 130-6. [Crossref]
109. Mu W, Cheng XF, Liu Y, Lv QZ, Liu GL, Zhang JG, et al. (2019) Potential nexus of non-alcoholic fatty liver disease and type 2 diabetes mellitus: Insulin resistance between hepatic and peripheral tissues. Front Pharmacol. 9: 1566. [Crossref]

110. Papp KA, Leonardi C, Menter A, Ortonne JP, Krueger JG, Kricorian G, et al. (2012) Brodalumab, an anti-interleukin-17-receptor antibody for psoriasis. N Engl J Med. 366(13): 1181-9. [Crossref]

111. Spuls PI, Hooft L. (2012) Brodalumab and ixekizumab, anti-interleukin-17receptor antibodies for psoriasis: a critical appraisal. Br J Dermatol. 167(4): 710-3; discussion 714-5. [Crossref]

112. Lockshin B, Balagula Y, Merola JF. (2018) Interleukin 17, inflammation, and cardiovascular risk in patients with psoriasis. J Am Acad Dermatol. 79(2): 345-352. [Crossref]

113. Ventura A, Mazzeo M, Gaziano R, Galluzzo M, Bianchi L, Campione E. (2017) New insight into the pathogenesis of nail psoriasis and overview of treatment strategies. Drug Des Devel Ther. 11: 2527-2535. [Crossref]

114. Shih CM, Huang CY, Wang KH, Huang CY, Wei PL, Chang YJ, et al. (2018) Oxidized low-density lipoprotein-deteriorated psoriasis is associated with the upregulation of Lox-1 receptor and Il-23 expression in vivo and in vitro. Int $\mathrm{J} \mathrm{Mol}$ Sci. 19(9). [Crossref]

115. Abbas A, Gregersen I, Holm S, Daissormont I, Bjerkeli V, Krohg-Sørensen K, et al. (2015) Interleukin 23 levels are increased in carotid atherosclerosis: Possible role for the interleukin 23/interleukin 17 axis. Stroke. 46(3): 793-9. [Crossref]

116. Di Cesare A, Di Meglio P, Nestle FO. (2009) The IL-23/Th17 axis in the immunopathogenesis of psoriasis. J Invest Dermatol. 129(6): 1339-50. [Crossref]

117. Fashanu OE, Oyenuga AO, Zhao D, Tibuakuu M, Mora S, Otvos JD, et al. (2019) GlycA, a novel inflammatory marker and its association with peripheral arterial disease and carotid plaque: the multi-ethnic study of atherosclerosis. Angiology. 70(8): 737-746. [Crossref]

118. Joshi AA, Lerman JB, Aberra TM, Afshar M, Teague HL, Rodante JA, et al. (2016) GlycA is a novel biomarker of inflammation and subclinical cardiovascular disease in psoriasis. Circ Res. 119(11): 1242-1253. [Crossref]

119. Montaudié H, Albert-Sabonnadière C, Acquacalda E, Fontas E, Danré A, Roux C, et al. (2014) Impact of systemic treatment of psoriasis on inflammatory parameters and markers of comorbidities and cardiovascular risk: results of a prospective longitudinal observational study. J Eur Acad Dermatol Venereol. 28(9): 1186-91. [Crossref]

120. Jiang S, Hinchliffe TE, Wu T. (2015) Biomarkers of an autoimmune skin disease-Psoriasis. Genomics Proteomics Bioinformatics. 13(4): 224-33. [Crossref]

121. Mansouri B, Patel M, Menter A. (2013) Biological therapies for psoriasis. Expert Opin Biol Ther. 13(12): 1715-30. [Crossref]

122. Kamleh MA, Snowden SG, Grapov D, Blackburn GJ, Watson DG, Xu N, et al. (2015) LC-MS metabolomics of psoriasis patients reveals disease severitydependent increases in circulating amino acids that are ameliorated by anti-TNF $\alpha$ treatment. J Proteome Res. 14(1): 557-66. [Crossref]

123. Späh F. (2008) Inflammation in atherosclerosis and psoriasis: common pathogenic mechanisms and the potential for an integrated treatment approach. Br J Dermatol. 159 Suppl 2: 10-7. [Crossref]

124. Wakkee M, Thio HB, Prens EP, Sijbrands EJ, Neumann HA. (2007) Unfavorable cardiovascular risk profiles in untreated and treated psoriasis patients. Atherosclerosis. 190(1): 1-9. [Crossref]

125. Ridker PM, Everett BM, Pradhan A, MacFadyen JG, Solomon DH, Zaharris E, et al. (2019) Low-dose methotrexate for the prevention of atherosclerotic events. $N$ Engl J Med. 380(8): 752-762. [Crossref]

126. Rungapiromnan W, Yiu ZZN, Warren RB, Griffiths CEM, Ashcroft DM. (2017) Impact of biologic therapies on risk of major adverse cardiovascular events in patients with psoriasis: systematic review and meta-analysis of randomized controlled trials. Br J Dermatol. 176(4): 890-901. [Crossref]

127. Lee MP, Desai RJ, Jin Y, Brill G, Ogdie A, Kim SC. (2019) Association of ustekinumab vs TNF inhibitor therapy with risk of atrial fibrillation and cardiovascular events in patients with psoriasis or psoriatic arthritis. JAMA Dermatol. 155(6): 700-707. [Crossref]

\section{Citation:}

Carmen Rodríguez-Cerdeira, Erick Martínez -Herrera, Miguel CarneroGregorio, Adriana López-Barcenas, Mónica Cordeiro-Rodríguez, Gabriella Fabbrocini, Ardiana Sinani, Brunilda Bardhi, José Luís González-Cespón (2020) Measurement and Clinical Significance of Novel Inflammatory Biomarkers in Patients with Psoriasis and Cardiovascular Risk Factors for the Primary Care Practitioner. J Clin Res Med Volume 3(1): 1-14. 